\title{
Insulin Tolerance Test under Anaesthesia to Measure Tissue-specific Insulin-stimulated Glucose Disposal
}

\author{
Daniel J. Fazakerley ${ }^{1, \#}$, Andreas M. Fritzen ${ }^{1,2, \#, ~ M a r i n ~ E . ~ N e l s o n ~}{ }^{1}$, Ida H. Thorius ${ }^{1,2}$, \\ Kristen C. Cooke ${ }^{1}$, Sean J. Humphrey ${ }^{1}$, Gregory J. Cooney ${ }^{3}$ and David E. James ${ }^{1,3, *}$
}

${ }^{1}$ Charles Perkins Centre, School of Life and Environmental Sciences, University of Sydney, Camperdown, New South Wales 2006, Australia; ${ }^{2}$ Section of Molecular Physiology, Department of Nutrition, Exercise and Sports, Faculty of Science, University of Copenhagen, Copenhagen 2200, Denmark; ${ }^{3}$ Charles Perkins Centre, Sydney Medical School, University of Sydney, Camperdown, New South Wales 2006, Australia

*For correspondence: david.james@sydney.edu.au

\#Contributed equally to this work

\begin{abstract}
[Abstract] Insulin resistance is a pathophysiological state defined by impaired responses to insulin and is a risk factor for several metabolic diseases, most notably type 2 diabetes. Insulin resistance occurs in insulin target tissues including liver, adipose and skeletal muscle. Methods such as insulin tolerance tests and hyperinsulinaemic-euglycaemic clamps permit assessment of insulin responses in specific tissues and allow the study of the progression and causes of insulin resistance. Here we detail a protocol for assessing insulin action in adipose and muscle tissues in anesthetized mice administered with insulin intravenously.
\end{abstract}

Keywords: Insulin, Adipose tissue, Muscle, Glucose transport, Glucose uptake, Insulin tolerance test

[Background] Surrogate measures of whole-body insulin sensitivity such as homeostatic model assessment for insulin resistance (HOMA-IR) often do not reflect insulin-stimulated glucose uptake in peripheral tissues of the mouse (Lee et al., 2008; Mather, 2009). Ex vivo adipose tissue explants or isolated skeletal muscles preparations (Burchfield et al., 2018; Fazakerley et al., 2018b) can allow direct measurement of insulin responses in specific tissues if they are amenable to these procedures, but do not preserve the organism environment where finely articulated delivery of glucose and insulin via the vasculature, uptake into cells and intracellular metabolism may all contribute to the overall rate of tissue glucose uptake (Wasserman et al., 2011). Commonly employed methods to assess whole-body insulin action in mice include intraperitoneal (IP) or intravenous insulin tolerance tests (ITTs) and, the gold standard, hyperinsulinaemic-euglycaemic clamp (Ayala et al., 2010; Brandon et al., 2016). These techniques can assess whole-body insulin action by measuring either changes in blood glucose (ITT) or changes in the amount of glucose required to maintain glycemia (glucose infusion rate; hyperinsulinaemic-euglycaemic clamp) and can be adapted to measure tissue-specific insulin responses. For example, glucose tracers such as radiolabeled 2-deoxyglucose (2-DOG), which is often used as a surrogate for glucose in assessing glucose uptake as it is not metabolized through glycolysis and is 'trapped' in the cells following uptake, can be introduced to permit assessment of glucose uptake 
into specific tissues during these tests. Note that 2-DOG is only trapped in tissues that do not possess significant glucose-6-phosphatase activity, and so 2-DOG tracer is therefore not useful for assessing glucose disposal in the liver.

Both ITTs and hyperinsulinaemic-euglycaemic clamps can be performed in conscious or anesthetized mice. Certain anesthetics affect whole-body glucose metabolism and should therefore be avoided when assessing insulin action or glucose homeostasis [e.g., isoflurane (Pomplun et al., 2004; Tanaka et al., 2009; Windelov et al., 2016; Hoyer et al., 2018)]. However, anesthetics that minimally affect glucose metabolism, such as pentobarbitone (Guarino et al., 2013), may actually be advantageous for studying insulin-stimulated glucose uptake. This is because insulin-stimulated 2-DOG/glucose uptake in conscious mice may be affected by movement (e.g., due to mechanical- and/or exercise- stimulated glucose uptake) and/or stress responses [e.g., catecholamines (Cooney et al., 1985; Furler et al., 1991) and glucocorticoids (Pasieka and Rafacho, 2016)].

Here, we describe a protocol for a terminal intravenous ITT performed under pentobarbitone-induced anesthesia to assess insulin-stimulated glucose uptake into tissues of interest. The protocol can be performed with minimal delays between mice, making it amenable to assessing insulin action in large cohorts of animals. Intravenous administration of a bolus of insulin/tracer rapidly delivers insulin to tissues, minimizing the time between the start of the assay and initiation of insulin responses within tissues. Also, rapid equilibration of the 2-DOG tracer with the total blood glucose pool ensures that the tracer is immediately available for uptake into tissues. Alternative methods of insulin/tracer delivery (i.e., intraperitoneal injection, oral gavage) may result in delays or inconsistent insulin/tracer uptake into the central circulation. For example, in the case of IP injection, there may be a considerable delay before insulin reaches the circulation. These time lags may differ between mice or between injections, increasing experimental variability. Rapid and consistent tissue uptake is also particularly important when performing time-series experiments in live animals. Indeed, hepatic portal-vein administration of insulin has enabled the assessment of the time-resolved effects of insulin on the liver phosphoproteome (Humphrey et al., 2015). For oral gavage, 2-DOG may exhibit markedly different kinetics of appearance in the circulation compared to glucose since the sodium-dependent glucose transporters, which play a key role in oral glucose absorption, exhibit a strong preference for glucose (Bissonnette et al., 1996), and this may limit tracer availability to tissues during the assay.

In this protocol, mice are anesthetized with pentobarbitone and saline or insulin and radiolabeled 2DOG tracer administered via the hepatic portal vein. Insulin action in muscle and adipose tissues of interest can be assessed via Western blotting for insulin signaling intermediates or through measuring radiolabeled 2-DOG tracer accumulation as an index of glucose uptake.

\section{Materials and Reagents}

1. Pipette tips (e.g., Axygen, catalog numbers: T-1000-C, T-200-C)

2. Cotton bud (e.g., McFarlane Medical Equipment, catalog number: 18049DE)

3. $1.5 \mathrm{ml}$ microfuge tubes (Axygen, catalog number: MCT-150-C) 
4. $2.0 \mathrm{ml}$ microfuge tubes (Eppendorf, catalog number: 0030120.094)

5. $5 \mathrm{ml}$ polystyrene tubes (SARSTEDT, catalog number: 60.9921.531)

6. $0.5 \mathrm{ml}$ Ultra-Fine Insulin Syringes (Becton Dickinson, catalog number: 230-45094)

7. Masking tape (e.g., Lyreco, catalog number: 737.665)

8. 96-well plates (Corning, catalog number: CLS2595)

9. Carbon Steel, size 22 scalpel blades (Livingstone, catalog number: SBLDCL22)

10. Chromatography columns (Bio-Rad, catalog number: 731-1550)

11. $6 \mathrm{ml}$ pony vial scintillation tubes (PerkinElmer, catalog number: 6000292)

12. Adult mice (> 8 weeks old)

Note: Ensure experiments using mice are carried with the approval of local ethics committee. Mice may be subjected to different dietary/exercise regimes or be knockout/transgenic lines for genes of interest. For knockout/transgenic lines we recommend using littermate controls.

13. Double-distilled water $\left(\mathrm{ddH}_{2} \mathrm{O}\right)$

14. Bicinchoninic acid assay (BCA) protein assay kit (Thermo Fisher Scientific, catalog number: 23225)

15. Antibodies
a. Anti-phospho-Thr308 Akt antibody (Cell Signaling Technology, catalog number: 9275)
b. Anti-phospho-Ser473 Akt antibody (Cell Signaling Technology, catalog number: 4051)
c. Anti-Akt antibody (Cell Signaling Technology, catalog number: 4685)

16. Pentobarbitone (Lethabarb, Virbac, Australia)

Note: Pentobarbitone may be a regulated substance. Ensure that use follows local regulations.

17. Human insulin (Actrapid, Novo Nordisk)

18. $0.9 \%$ Sodium Chloride Injection BP (Pfizer, catalog number: 158594)

19. $\left[{ }^{3} \mathrm{H}\right] 2-\mathrm{DOG}$ (PerkinElmer, catalog number: NET328001MC)

20. Accu-Chek performa Glucose Strips (Accu-Check II; Roche Diagnostics, catalog number: 06454038)

21. Liquid nitrogen

22. AG1-X8 resin (Bio-Rad, catalog number: 140-1443)

23. Ulitma Gold XR Scintillation fluid (PerkinElmer, catalog number: 6013119)

24. Barium hydroxide (Sigma, catalog number: 433373)

25. Dry ice

26. $2.75 \%$ zinc sulfate solution (see Recipes)

Zinc sulfate $\left(\mathrm{ZnSO}_{4}\right)$ (Sigma, catalog number: 307491 )

27. Phosphorylated $\left[{ }^{3} \mathrm{H}\right] 2-\mathrm{DOG}$ elution buffer (see Recipes):
a. Trifluoroacetic acid (Sigma, catalog number: 302031)
b. $\mathrm{NaCl}$ (Sigma, catalog number: S7653)

28. Western blot lysis buffer (see Recipes):
a. HEPES (Sigma, catalog number: 54457)
b. Sucrose (Sigma, catalog number: S8501) 
c. EDTA (Sigma, catalog number: 03620)

d. SDS (Sigma, catalog number: 71729)

e. Protease inhibitors (Roche, cOmplete ${ }^{\mathrm{TM}}$, catalog number: 11697498001)

f. Sodium pyrophosphate (Sigma, catalog number: 71501)

g. Sodium orthovanadate (Sigma, catalog number: S6508)

h. Sodium fluoride (Sigma, catalog number: S7920)

\section{Equipment}

1. Scalpel or surgical scissors (e.g., World Precision Instruments, catalog number: 501259-G)

2. Pipettes (P20, P200, P1000) (e.g., Finnpipette F1 Pipettes, Thermo Fisher Scientific, catalog numbers: $4641050 \mathrm{~N}, 4641080 \mathrm{~N}, 4641100 \mathrm{~N})$

3. Echo-magnetic resonance imaging (MRI) scanner (Echo Medical Systems LLC, model: EchoMRI-4 in $1^{\mathrm{TM}}$ for Live Animals,) to assess mouse lean mass for insulin and pentobarbitone dosing

4. Heat pads (Able Scientific, catalog number: ASCHP-RP)

5. Blood glucometer (Roche Diagnostics, model: Accu-Check II)

6. Mortar and pestle for tissue preparation (e.g., Maxwell \& Williams, catalog number: AA1891)

7. Ultrasonic tip-probe sonicator/homogenizer (Bendelin, model: Sonopuls)

8. Refrigerated centrifuge (Thermo Fisher Scientific, model: Heraeus Fresco 21)

9. Vortex (Ratek, model: VM1)

10. Scintillation Counter (Beckman Coulter, model:LS6500)

\section{Software}

1. Microsoft Excel or GraphPad Prism

\section{Procedure}

A. Hepatic portal vein cannulation

1. Determine mouse lean mass by ECHO-MRI according to the manufacturer's instructions 24-48 $\mathrm{h}$ prior to procedure.

2. Remove food at least $2 \mathrm{~h}$ prior to starting experiment, depending on study requirements.

3. Prepare a 96-well plate containing $75 \mu \mathrm{l} 2.75 \% \mathrm{ZnSO}_{4}$ per well for blood collection during the procedure. Prepare enough wells for collection of blood at 6 time points per mouse. Keep plate on ice throughout the procedure.

4. Inject mice with $80 \mathrm{mg} / \mathrm{kg}$ lean mass (determined by ECHO-MRI) pentobarbitone intraperitoneally. Mice with increased adiposity may require more pentobarbitone, up to $80 \mathrm{mg} / \mathrm{kg}$ body weight. See Videos 1 and 2 . 


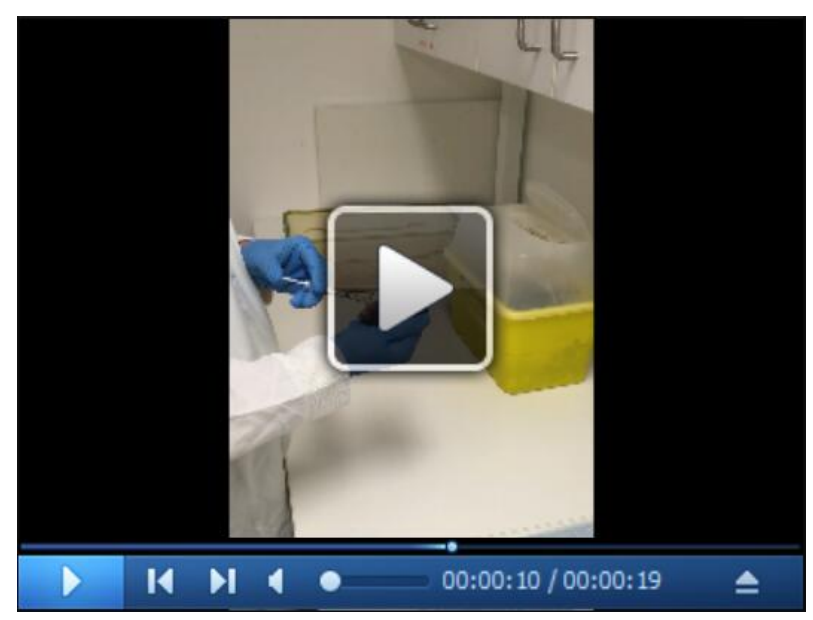

Video 1. Intraperitoneal injection of pentobarbitone (This video was made at The University of Sydney. Procedures were approved by The University of Sydney Animal Ethics Committee under project \# 2017/1274)

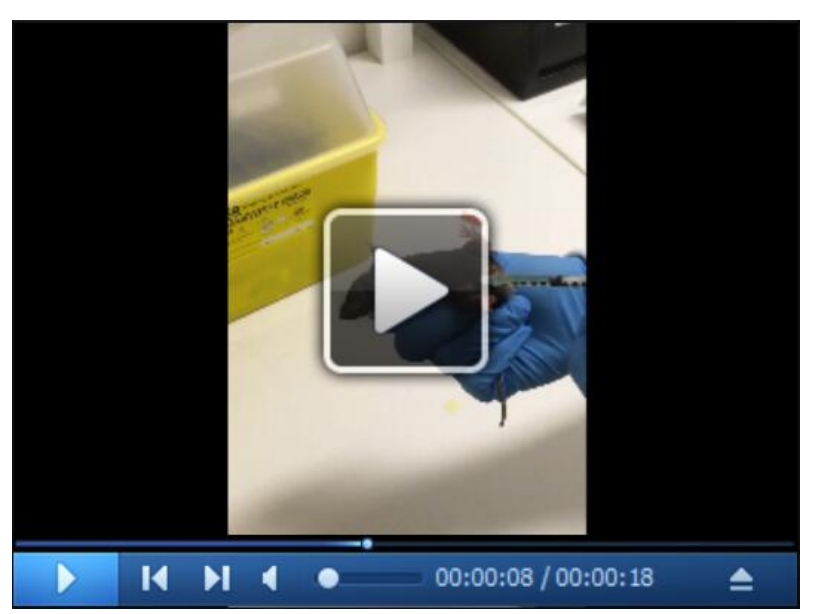

Video 2. Intraperitoneal injection of pentobarbitone (close up) (This video was made at The University of Sydney. Procedures were approved by The University of Sydney Animal Ethics Committee under project \# 2017/1274)

5. Assess the quality of anesthesia using the toe-pinch reflex once the animal appears to be fully unconscious. When the mouse does not respond (approximately 15-20 min after injection), place animal on back (dorsal recumbency) on a heat pad $\left(\sim 30^{\circ} \mathrm{C}\right)$ and secure the limbs to the surface using tape.

Note: In the event that a mouse still has a toe-pinch reflex 20 min post-anesthetic, administer up to $20 \%$ more pentobarbitone and test for toe-pinch reflex again after $10 \mathrm{~min}$. Euthanize mouse if still responsive.

6. Cut the tip ( $1 \mathrm{~mm}$ ) off the tail with a scalpel blade. Take a baseline blood glucose measurement from a drop of blood taken from the tail using a glucometer. Take $5 \mu \mathrm{l}$ blood from the tail for scintillation counting to act as a background sample. Add this $5 \mu \mathrm{l}$ blood to one well of a 96-well plate containing $75 \mu \mathrm{l} 2.75 \% \mathrm{ZnSO}_{4}$. 
7. Make a $3 \mathrm{~cm}$ incision through the skin and peritoneum using a scalpel or surgical scissors across the midline and perpendicular up towards the rib cage to open the abdominal cavity. Avoid puncturing the diaphragm. See Video 3.

8. Using a blunt sterile implement (e.g., cotton bud moistened with saline), carefully move the intestines to the right and the liver right and left medial lobes upward toward the ribcage to expose the hepatic portal vein and inferior vena cava (Figure 1A). See Video 3.

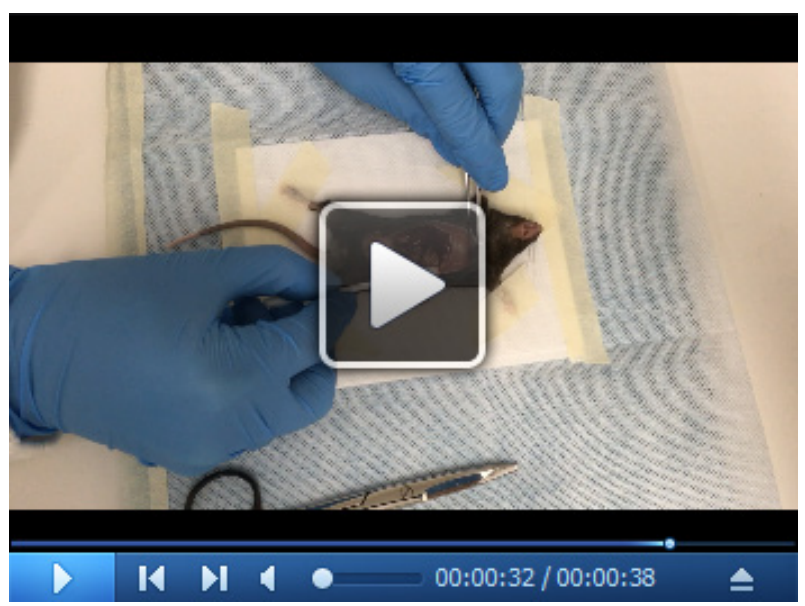

Video 3. Surgery to access the hepatic portal vein (This video was made at The University of Sydney. Procedures were approved by The University of Sydney Animal Ethics Committee under project \# 2017/1274)

9. Using a 25-29 G insulin syringe, inject a bolus of saline (for non-insulin-stimulated glucose uptake) or insulin (for insulin-stimulated glucose uptake; $1 \mathrm{U} / \mathrm{kg}$ lean body mass) containing 5$10 \mu \mathrm{Ci}\left[{ }^{3} \mathrm{H}\right] 2-\mathrm{DOG}$ tracer into the hepatic portal vein (Figures $1 \mathrm{~A}$ and $1 \mathrm{~B}$ ) or inferior vena cava if preferred. See Video 4 and Figure 1.

Note: Ensure that use of radioactive material is performed following local guidelines and regulations, including appropriate use of protective equipment, safe work practices, cleaning of workspaces after experiments and waste disposal. 


\section{biö-protocol

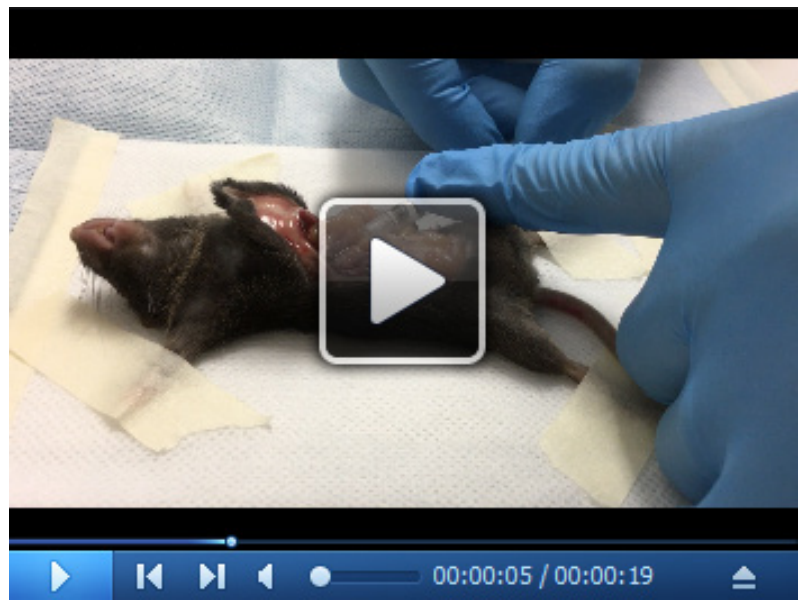

Video 4. Administration of saline to the hepatic portal vein. (This video was made at The University of Sydney. Procedures were approved by The University of Sydney Animal Ethics Committee under project \# 2017/1274)

10. The needle can either:

a. Be rested to the side and left in the vein (Figure 1B).

b. Be removed and a clamp applied to minimize bleeding.

A

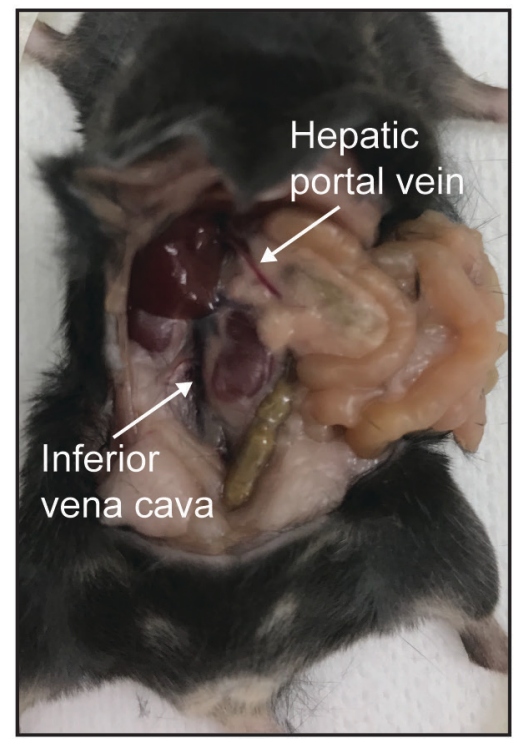

B

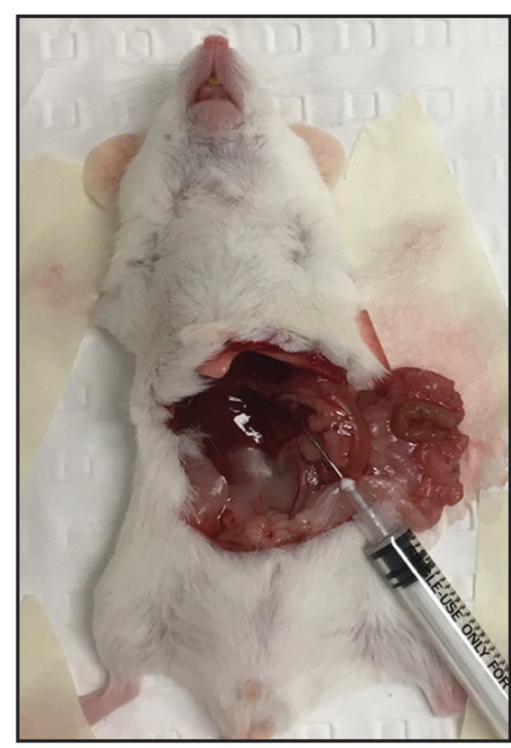

Figure 1. Hepatic portal vein cannulation in anesthetized mice. A. Location of the hepatic portal vein or inferior vena cava in mice. B. Picture of a Balb/c mouse during experiment where saline/insulin and tracer was injected via the hepatic portal vein and needle left in for the duration of the study.

11. Measure blood glucose (from tail) and collect $5 \mu \mathrm{l}$ blood (and add to $\mathrm{ZnSO}_{4}$ as in Step A6) per mouse to determine blood radioactivity after $2,5,10,15,20$, and $30 \mathrm{~min}$. 
12. After $30 \mathrm{~min}$, terminate the mouse by cervical dislocation and excise tissues of interest (e.g., quadriceps muscle, tibialis anterior muscle, gastrocnemius muscle, epididymal adipose tissue, inguinal adipose tissue, heart). Tissues should be snapped frozen in liquid nitrogen and stored at $-80{ }^{\circ} \mathrm{C}$ until further analysis. Tissues can be weighed before or after freezing.

Note: Mice should be culled at a time where blood tracer counts are still decreasing and have not plateaued. We typically perform $30 \mathrm{~min}$ ITTs.

B. Western blot preparation

1. Weigh out $50 \mathrm{mg}$ epididymal white adipose tissue or muscle on dry ice, keeping the tissue frozen.

2. Add $250 \mu \mathrm{l}$ of Western Blot Lysis Buffer to frozen tissue and immediately homogenize by sonication (90\% power, $3 \times 10 \mathrm{~s}$, allowing sample to cool between pulses).

3. Centrifuge at $13,000 \times g$ for $10 \mathrm{~min}$ at $12{ }^{\circ} \mathrm{C}$.

4. Remove the supernatant for muscle tissue, or carefully remove the infranatant for adipose tissue, being careful not to disturb the lipid layer.

5. Determine protein concentration using BCA or similar protein assay and prepare samples for Western blot as per standard protocol using phospho-specific antibodies to signaling intermediates of interest (e.g., phospho-and total Akt) (Figure 2).

Note: Care should be taken to ensure that waste from SDS-PAGE is disposed of according to local regulations since samples contain radioactivity.

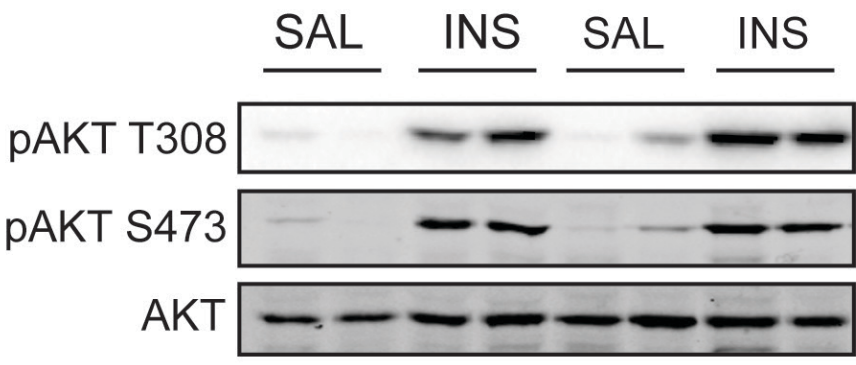

Figure 2. Assessment of insulin signaling in adipose tissue. Adipose tissue was excised from mice administered with saline or insulin. Phosphorylation of Akt at activating sites (Thr308 and Ser473) was assessed by Western blotting with phospho-specific antibodies. Insulin increased Akt phosphorylation at both sites.

C. Tracer disappearance and uptake

1. To measure tracer disappearance from the blood, add $25 \mu \mathrm{l}$ of a saturated $\mathrm{Ba}(\mathrm{OH})_{2}$ solution (in $\mathrm{ddH}_{2} \mathrm{O}$ ) to wells containing blood samples in $\mathrm{ZnSO}_{4}$ (Step A5 above, final volume $105 \mu \mathrm{l}$ ). This deproteinizes the samples. Centrifuge the 96 -well plate at $1,000 \times g$ for $5 \mathrm{~min}$ to pellet precipitated protein and transfer $50 \mu \mathrm{l}$ of the cleared sample to a scintillation vial and add $3 \mathrm{ml}$ of scintillant. Count ${ }^{3} \mathrm{H}$ DPM in each sample using a liquid scintillation counter. 
2. To measure tracer uptake into a tissue of interest, powder tissue in liquid nitrogen using a mortar and pestle and then weigh an aliquot of powder for analysis. Smaller tissues such as the soleus muscle can be homogenized according to Step $\mathrm{C} 3$ and do not require powdering.

3. Homogenize $\sim 40 \mathrm{mg}$ tissue (as little as $10 \mathrm{mg}$ soleus and EDL muscle can be used) in $1 \mathrm{ml}$ $\mathrm{ddH}_{2} \mathrm{O}$ in a $1.5 \mathrm{ml}$ tube by sonication ( $90 \%$ power, $3 \times 10 \mathrm{~s}$, allowing sample to cool between pulses) and centrifuge at $13,000 \times g$ for $15 \mathrm{~min}$. Collect supernatant $(\sim 800 \mu \mathrm{l})$ and transfer to a new $2.0 \mathrm{ml}$ tube. Bring up volume to $2 \mathrm{ml}$ with $\mathrm{ddH}_{2} \mathrm{O}$.

4. Prepare the phospho-2-DOG affinity elution columns by adding $1 \mathrm{ml} A G 1-X 8$ resin diluted in $\mathrm{ddH}_{2} \mathrm{O}$ ( $70 \%$ volume resin) to a $0.8 \times 4 \mathrm{~cm}$ chromatography column using a wide-bore pipette tip (e.g., P1000 tip cut $5 \mathrm{~mm}$ from the tip using a scalpel blade to increase the aperture).

5. Place $5 \mathrm{ml}$ tubes below the columns and add $1 \mathrm{ml}$ of the supernatant to the columns followed by three $1 \mathrm{ml}$ washes with $\mathrm{dd}_{2} \mathrm{O}$.

6. Place new scintillation vials below the columns and add $1 \mathrm{ml}$ of the elution buffer (see Recipes below) to columns followed by another $1 \mathrm{ml}$ of elution buffer.

7. Add $3 \mathrm{ml}$ scintillation fluid (PerkinElmer) to the scintillation vials, vortex thoroughly, and measure ${ }^{3} \mathrm{H}$ DPM in each sample using a liquid scintillation counter to quantify $\left[{ }^{3} \mathrm{H}\right] 2-\mathrm{DOG}-6-\mathrm{P}$.

\section{Data analysis}

The aim of data analysis is to normalize for the amount of tracer delivered to each mouse and available for uptake into tissues, and the amount of tissue analyzed. Methods for normalizing such data have been discussed extensively elsewhere (Sokoloff et al., 1977; Goodner et al., 1980; Hom et al., 1984; Cooney et al., 1985; Kraegen et al., 1985).

We describe two methods below: 1) the data are normalized to tracer availability in the blood to calculate the amount of tracer taken into the tissue of interest as a proportion of the amount of tracer available to the tissue, and 2) approximate an index of glucose uptake into tissues by using DPM and blood glucose to calculate a specific activity (DPM/mol glucose). In each case, data can be expressed per unit weight and/or protein/DNA content of the analyzed tissue.

Note: The methods described below use an area under the curve (AUC) calculation to normalize for tracer availability to tissues. This method works best if mice are culled when blood tracer counts are decreasing and have not plateaued. We typically perform 30 min ITTs.

1. To calculate tracer 2-DOG clearance into specific tissues as a proportion of total 2-DOG available to the tissue:

This calculation assumes that the 2-DOG tracer measured by a tail bleed is indicative of tracer available in the interstitial space for uptake into the tissue.

First, extrapolate DPM per $5 \mu \mathrm{l}$ to $1 \mathrm{ml}$ to yield DPM/ml. Since the tracer will disappear from the blood by an exponential decay, calculate the AUC by fitting the DPM/ml at measured time points to a single exponential function, and integrate this function over the experimental period. 
This estimates the change in blood DPM/ml throughout the experiment (DPM/ml $\cdot \mathrm{min})$. This AUC value provides a normalization factor that takes into account differences in tracer availability between mice.

Tissue DPMs can be normalized using this AUC value to calculate the proportion of available tracer taken up into the tissue. This can be further normalized to the weight of tissue analyzed (g). The final units are: 2-DOG clearance $(\mathrm{ml} / \mathrm{min} / \mathrm{g})$. Data normalized using this method are presented in Figures $3 \mathrm{~A}$ and 3B. These data show insulin-stimulated 2-DOG clearance into muscle and adipose tissues, but not into brain (Figure $3 A$ ) and that feeding mice a diet high in fat and sucrose leads to impaired insulin-stimulated 2-DOG clearance into epididymal adipose tissue and quadriceps muscle (Figure 3B).

2. To obtain a tissue-specific index of glucose uptake:

The blood glucose concentration during this assay is non-steady-state. This calculation aims to take into account differences in blood glucose over the course of the experiment and approximate glucose uptake into tissue. This calculation assumes that there is no discrimination between 2-DOG and glucose at the glucose transporter and therefore the rate of [ $\left.{ }^{3} \mathrm{H}\right] 2-\mathrm{DOG}$ accumulation in tissue is equivalent to the rate of glucose uptake into tissue (Ferre et al., 1985). Since the kinetics of 2-DOG and glucose uptake may differ, we advise referring to 2-DOG accumulation as a "glucose uptake index".

First calculate the AUC for blood DPM (as above by exponential curve fitting; DPM $/ \mathrm{ml} \cdot \mathrm{min}$ ) and blood glucose during the ITT (by the trapezoidal method; $\mu \mathrm{mol} / \mathrm{ml} \cdot \mathrm{min}$ ). The average specific activity of 2-DOG in the blood can be calculated by dividing the blood DPM AUC by blood glucose AUC (DPM/ $/ \mu \mathrm{mol})$. Tissue DPM can then be converted to an index for the rate of glucose uptake by dividing by the average specific activity, and further normalized to the weight of tissue analyzed $(\mathrm{g})$ and expressed per min or $\mathrm{h}$. The final units are: Glucose uptake index $(\mu \mathrm{mol} / \mathrm{g} / \mathrm{h})$. Data normalized using this method are presented in Figure 3B. These data show that feeding mice a high fat high sucrose diet for $14 \mathrm{~d}$ lowers the insulin-stimulated glucose uptake index in epididymal adipose tissue and quadriceps muscle (Figure $3 \mathrm{C}$ ).

A

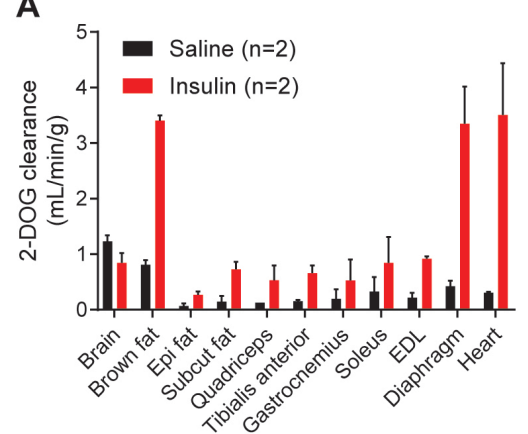

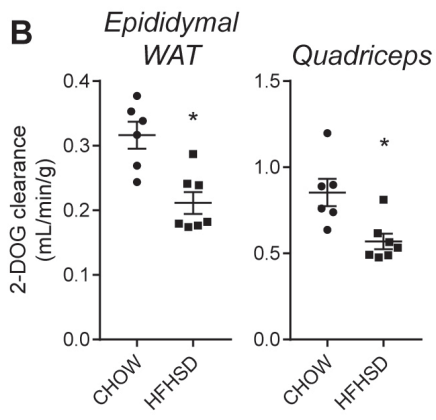

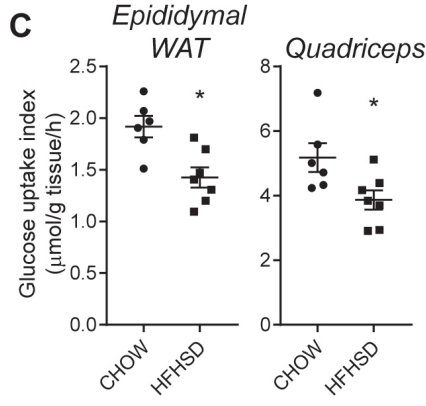

Figure 3. 2-DOG uptake into tissues. A. 2-DOG clearance into indicated tissues was assessed in C57BI/6J mice following saline or insulin administration (Epi; Epididymal, Subcut; subcutaneous/inguinal, EDL; Extensor digitorum longus). Adipose and muscle tissues exhibited 
insulin-responsive 2-DOG clearance. B and C. Insulin-stimulated 2-DOG clearance (B) or glucose uptake index (C) for epididymal white adipose tissue (WAT) (left inset) and quadriceps muscle (right inset) in C57BI/6J mice fed a chow diet or high fat high sucrose diet (HFHSD). ${ }^{*} P<0.05$ versus mice fed a chow diet, Student's $t$-test, $\mathrm{n}=6-7$. Data in $\mathrm{B}$ and $\mathrm{C}$ were recalculated from Fazakerley et al. (2018a).

\section{Recipes}

1. $2.75 \%$ zinc sulfate solution

$100 \mathrm{ml}$ of $2.75 \%$ zinc sulfate contains $4.44 \mathrm{~g}$ zinc sulfate in $\mathrm{ddH}_{2} \mathrm{O}$

2. Phosphorylated $\left[{ }^{3} \mathrm{H}\right] 2-\mathrm{DOG}$ elution buffer

Low $\mathrm{pH}$, high salt solution (e.g., $1 \%$ Trifluoroacetic acid, $2 \mathrm{M} \mathrm{NaCl}$ )

$100 \mathrm{ml}$ of elution buffer contains $1 \mathrm{ml} 100 \%$ Trifluoracetic acid and $11.69 \mathrm{~g} \mathrm{NaCl}$ in $\mathrm{ddH}_{2} \mathrm{O}$

3. Western blot lysis buffer

$10 \mathrm{mM}$ HEPES, $\mathrm{pH} 7.4$

$250 \mathrm{mM}$ sucrose

1 mM EDTA

$2 \%$ SDS

Protease and phosphatase inhibitors (1 $\mathrm{mM}$ sodium pyrophosphate, $2 \mathrm{mM}$ sodium orthovanadate, $10 \mathrm{mM}$ sodium fluoride)

We advise making 10x stocks of HEPES pH 7.4, sucrose, EDTA and SDS.

$10 \mathrm{ml}$ of lysis buffer contains, $23.8 \mathrm{mg}$ HEPES, $855.6 \mathrm{mg}$ sucrose, $2.9 \mathrm{mg}$ EDTA, $576.8 \mathrm{mg}$ SDS,

$1 x$ Roche cOmplete ${ }^{T M}$ protease inhibitors, $1 \mathrm{mM}$ sodium pyrophosphate, $2 \mathrm{mM}$ sodium orthovanadate, $10 \mathrm{mM}$ sodium fluoride. Adjust the solution $\mathrm{pH}$ to 7.4

\section{Acknowledgments}

This protocol is a modified version of the protocol reported in Fazakerley et al., 2018a. This work was supported by National Health and Medical Research Council of Australia (NHMRC) Project Grants 1061122 and 1086850 (to D. E. J.). D.E.J. is a National Health and Medical Research Council of Australia Senior Principal Research Fellow. The contents of the published material are solely the responsibility of the individual authors and do not reflect the views of NHMRC. We thank Dr. James Krycer and Dr. Lake-Ee Quek for helpful discussion.

\section{Competing interests}

The authors have no competing interests to declare. 


\section{Ethics}

All experiments were carried out with the approval of the University of Sydney Animal Ethics Committee, following guidelines issued by the National Health and Medical Research Council of Australia.

\section{References}

1. Ayala, J. E., Samuel, V. T., Morton, G. J., Obici, S., Croniger, C. M., Shulman, G. I., Wasserman, D. H. and McGuinness, O. P. (2010). Standard operating procedures for describing and performing metabolic tests of glucose homeostasis in mice. Dis Model Mech 3(9-10): 525-534.

2. Bissonnette, P., Gagne, H., Coady, M. J., Benabdallah, K., Lapointe, J. Y. and Berteloot, A. (1996). Kinetic separation and characterization of three sugar transport modes in Caco-2 cells. Am J Physiol 270(5 Pt 1): G833-843.

3. Brandon, A. E., Stuart, E., Leslie, S. J., Hoehn, K. L., James, D. E., Kraegen, E. W., Turner, N. and Cooney, G. J. (2016). Minimal impact of age and housing temperature on the metabolic phenotype of $A c c 2^{-1-}$ mice. J Endocrinol 228(3): 127-134.

4. Burchfield, J. G., Kebede, M. A., Meoli, C. C., Stockli, J., Whitworth, P. T., Wright, A. L., Hoffman, N. J., Minard, A. Y., Ma, X., Krycer, J. R., Nelson, M. E., Tan, S. X., Yau, B., Thomas, K. C., Wee, N. K. Y., Khor, E. C., Enriquez, R. F., Vissel, B., Biden, T. J., Baldock, P. A., Hoehn, K. L., Cantley, J., Cooney, G. J., James, D. E. and Fazakerley, D. J. (2018). High dietary fat and sucrose results in an extensive and time-dependent deterioration in health of multiple physiological systems in mice. $J$ Biol Chem 293(15): 5731-5745.

5. Cooney, G. J., Caterson, I. D. and Newsholme, E. A. (1985). The effect of insulin and noradrenaline on the uptake of $2-\left[1-{ }^{14} \mathrm{C}\right]$ deoxyglucose in vivo by brown adipose tissue and other glucose-utilising tissues of the mouse. FEBS Lett 188(2): 257-261.

6. Fazakerley, D. J., Chaudhuri, R., Yang, P., Maghzal, G. J., Thomas, K. C., Krycer, J. R., Humphrey, S. J., Parker, B. L., Fisher-Wellman, K. H., Meoli, C. C., Hoffman, N. J., Diskin, C., Burchfield, J. G., Cowley, M. J., Kaplan, W., Modrusan, Z., Kolumam, G., Yang, J. Y., Chen, D. L., Samocha-Bonet, D., Greenfield, J. R., Hoehn, K. L., Stocker, R. and James, D. E. (2018a). Mitochondrial CoQ deficiency is a common driver of mitochondrial oxidants and insulin resistance. Elife 7: e32111.

7. Fazakerley, D. J., Minard, A. Y., Krycer, J. R., Thomas, K. C., Stockli, J., Harney, D. J., Burchfield, J. G., Maghzal, G. J., Caldwell, S. T., Hartley, R. C., Stocker, R., Murphy, M. P. and James, D. E. (2018b). Mitochondrial oxidative stress causes insulin resistance without disrupting oxidative phosphorylation. J Biol Chem 293(19): 7315-7328.

8. Ferre, P., Leturque, A., Burnol, A. F., Penicaud, L. and Girard, J. (1985). A method to quantify glucose utilization in vivo in skeletal muscle and white adipose tissue of the anaesthetized rat. Biochem J 228(1): 103-110. 
Please cite this article as: Fazakerley et. al., (2019). Insulin Tolerance Test under Anaesthesia to Measure Tissue-specific Insulin-stimulated Glucose

9. Furler, S. M., Jenkins, A. B., Storlien, L. H. and Kraegen, E. W. (1991). In vivo location of the rate-limiting step of hexose uptake in muscle and brain tissue of rats. Am J Physiol 261(3 Pt 1): E337-347.

10. Goodner, C. J., Hom, F. G. and Berrie, M. A. (1980). Investigation of the effect of insulin upon regional brain glucose metabolism in the rat in vivo. Endocrinology 107(6): 1827-1832.

11. Guarino, M. P., Santos, A. I., Mota-Carmo, M. and Costa, P. F. (2013). Effects of anaesthesia on insulin sensitivity and metabolic parameters in Wistar rats. In Vivo 27(1): 127-132.

12. Hom, F. G., Goodner, C. J. and Berrie, M. A. (1984). A [ [ ${ }^{3} \mathrm{H}[2$-deoxyglucose method for comparing rates of glucose metabolism and insulin responses among rat tissues in vivo. Validation of the model and the absence of an insulin effect on brain. Diabetes 33(2): 141-152.

13. Hoyer, K. F., Nielsen, T. S., Risis, S., Treebak, J. T. and Jessen, N. (2018). Sevoflurane impairs insulin secretion and tissue-specific glucose uptake in vivo. Basic Clin Pharmacol Toxicol. doi: 10.1111/bcpt.13087.

14. Humphrey, S. J., Azimifar, S. B. and Mann, M. (2015). High-throughput phosphoproteomics reveals in vivo insulin signaling dynamics. Nat Biotechnol 33(9): 990-995.

15. Kraegen, E. W., James, D. E., Jenkins, A. B. and Chisholm, D. J. (1985). Dose-response curves for in vivo insulin sensitivity in individual tissues in rats. Am J Physiol 248(3 Pt 1): E353-362.

16. Lee, S., Muniyappa, R., Yan, X., Chen, H., Yue, L. Q., Hong, E. G., Kim, J. K., and Quon, M. J. (2008). Comparison between surrogate indexes of insulin sensitivity and resistance and hyperinsulinemic euglycemic clamp estimates in mice. Am J Physiol Endocrinol Metab 294: (2) E261-270.

17. Mather, K. (2009). Surrogate measures of insulin resistance: of rats, mice, and men. Am J Physiol Endocrinol Metab 296(2): E398-399.

18. Pasieka, A. M. and Rafacho, A. (2016). Impact of glucocorticoid excess on glucose tolerance: clinical and preclinical evidence. Metabolites 6(3): E24.

19. Pomplun, D., Mohlig, M., Spranger, J., Pfeiffer, A. F. and Ristow, M. (2004). Elevation of blood glucose following anaesthetic treatment in C57BL/6 mice. Horm Metab Res 36(1): 67-69.

20. Sokoloff, L., Reivich, M., Kennedy, C., Des Rosiers, M. H., Patlak, C. S., Pettigrew, K. D., Sakurada, O. and Shinohara, M. (1977). The $\left[{ }^{14} \mathrm{C}\right]$ deoxyglucose method for the measurement of local cerebral glucose utilization: theory, procedure, and normal values in the conscious and anesthetized albino rat. $J$ Neurochem 28(5): 897-916.

21. Tanaka, K., Kawano, T., Tomino, T., Kawano, H., Okada, T., Oshita, S., Takahashi, A. and Nakaya, Y. (2009). Mechanisms of impaired glucose tolerance and insulin secretion during isoflurane anesthesia. Anesthesiology 111(5): 1044-1051.

22. Wasserman, D. H., Kang, L., Ayala, J. E., Fueger, P. T. and Lee-Young, R. S. (2011). The physiological regulation of glucose flux into muscle in vivo. J Exp Biol 214(Pt 2): 254-262.

23. Windelov, J. A., Pedersen, J., and Holst, J. J. (2016). Use of anesthesia dramatically alters the oral glucose tolerance and insulin secretion in C57BI/6 mice. Physiol Rep 4(11): e1282. 